R. Newsom

A. Luff

C. Wainwright

C. Canning

Southampton Eye Unit

Southampton General

Hospital

Southampton, UK

Shackleton Department of

Anaesthesia

Southampton General

Hospital

Southampton, UK

Mr R.S.B. Newsom

Vitreoretinal Unit

Moorfields Eye Hospital

City Road

London EC1V 2PD, UK

Tel: +44 (0)207 2533411 e-mail:

rbnewsom@dircon.co.uk

Received: 14 August 2000 Accepted in revised form: 6 April 2001

\section{UK survey of attitudes to local anaesthesia for vitreoretinal surgery}

\begin{abstract}
Background The use of local anaesthesia (LA) for vitreoretinal (VR) surgery is growing although surgeons in the UK traditionally use general anaesthesia.

Purpose To assess the use and attitudes towards local anaesthesia for VR surgery among the members of the British and Eire Association of Vitreo-retinal Surgeons (BEAVRS).

Methods A questionnaire was sent to members of BEAVRS. Use of LA was assessed for the following procedures: macular hole; diabetic vitrectomy; vitrectomy; cryopexy and gas; buckling and re-buckling procedures. Attitudes of surgeons generally using LA for primary retinal detachment surgery ( $>50 \%$ of cases) were compared with those generally using general anaesthesia (GA) (> $50 \%$ of cases). Results $33.6 \%$ of surgeons preferred LA for macular hole; $\mathbf{2 6 . 2 \%}$ for diabetic vitrectomy; $\mathbf{2 3 . 3} \%$ for vitrectomy, cryopexy and gas; $\mathbf{2 1 . 4 \%}$ for buckling procedures; and $\mathbf{9 . 3 5 \%}$ for rebuckling procedures. When surgeons routinely using LA were compared with those regularly using GA they considered LA less stressful for patients and surgeon, patients tolerant to longer operations, and buckling or redo surgery no more difficult under LA. However, both groups considered surgery on young patients and
\end{abstract}

R. NEWSOM, A.LUFF, C. WAINWRIGHT,

C. CANNING

rate. ${ }^{7,8}$ Problems with lack of anaesthesia, long operations, retrobulbar haemorrhage preventing emergency surgery and active vasovagal reflexes have been cited as reasons for avoiding the use of LA. ${ }^{9}$ However, in a recent series these have affected less than $1 \%$ of cases. $^{5}$

LA has resource benefits ${ }^{10}$ as patients under LA generally take less time in theatre ${ }^{7}$ and recover more rapidly. ${ }^{10}$ We therefore aimed to assess the use of LA for VR surgery in the UK and the attitudes of surgeons to LA.

\section{Methods}

A questionnaire was sent to 201 members of the BEAVRS surveying use of and attitudes to LA. LA usage was determined by giving five exemplar cases and asking whether LA would be used $0-25 \%, 26-50 \%, 51-75 \%$ or $76-100 \%$ of the time. The examplar cases were: (1) vitrectomy for macular hole; (2) vitrectomy for diabetic vitreous haemorrhage; (3) vitrectomy with drainage and cryopexy for retinal detachment; (4) supero-temporal buckle with cryopexy (first operation) for retinal detachment; and (5) re-buckling surgery. These examples were used to gauge the surgeons' indications for LA.

Opinions on eight issues related to LA usage were also sought. Surgeons were asked whether they strongly disagreed, disagreed, agreed or strongly agreed with the statements: (1) LA is more stressful/painful for patients; (2) LA is more stressful for the surgeon; (3) younger patients tolerate LA poorly; (4) scleral buckling is more difficult under LA; (5) redo surgery is more difficult under LA; (6) teaching is more difficult under LA; (7) patients are intolerant to long ( $>1 \mathrm{~h}$ ) operations under LA; (8) sedation is rarely necessary with LA.

The age, clinical grade and further comments of the surgeon were requested and the responses were returned on anonymous forms. with several LA methods including peribulbar, $^{4-6}$ retrobulbar, ${ }^{7}$ sub-Tenon's injections ${ }^{8}$ and even topical anaesthesia with sedation. ${ }^{1,2}$ However, the reported uptake of LA for VR surgery has been more cautious in the UK. ${ }^{7}$ Recent papers from UK centres have shown LA to be effective (even during longer operations) and gives high patient satisfaction

\section{Statistical methods}

The proportion of surgeons preferring LA for each procedure was calculated and the $95 \%$ confidence interval $(\mathrm{CI})$ was calculated using the binomial exact method. For clarity of 
Table 1. The use of local anaesthesia (LA) by category of operation: 0-50\% surgeon preference was general anaesthesia, 51-100\% surgeon preference was $L A$

\begin{tabular}{lccccc}
\hline & \multicolumn{5}{c}{$\begin{array}{c}\text { Exemplar cases } \\
\text { No. of surgeons (\%) }\end{array}$} \\
\cline { 2 - 6 } $\begin{array}{l}\text { Percentage of } \\
\text { procedures under LA }\end{array}$ & $\begin{array}{c}\text { Macular } \\
\text { hole }\end{array}$ & $\begin{array}{c}\text { Diabetic } \\
\text { vitrectomy }\end{array}$ & $\begin{array}{c}\text { Vitrectomy, } \\
\text { cryopexy, gas }\end{array}$ & $\begin{array}{c}\text { Cryopexy, } \\
\text { buckle }\end{array}$ & Re-buckling \\
\hline $0-25 \%$ & $59(55.1)$ & $58(54.2)$ & $64(59.8)$ & $71(66.4)$ & $86(80.4)$ \\
$26-50 \%$ & $12(11.2)$ & $21(19.6)$ & $18(16.8)$ & $13(12.1)$ & $11(10.3)$ \\
$51-75 \%$ & $15(14.0)$ & $14(13.1)$ & $10(9.3)$ & $10(9.3)$ & $4(3.7)$ \\
$76-100 \%$ & $21(19.6)$ & $14(13.1)$ & $15(14.0)$ & $13(12.1)$ & $6(5.6)$ \\
\hline
\end{tabular}

presentation surgeons were divided in those preferring to use LA and those preferring to use general anaesthesia (GA) for primary retinal detachment repairs. Attitudes towards LA were compared between the two groups using the chi-squared test.

\section{Results}

Questionnaires were sent to $201 \mathrm{VR}$ surgeons. There were $122 / 201$ responses $(60.1 \%)$, of which 10 were unusable (returned unmarked, etc.) leaving 112/201 (55.7\%) analysable responses. Of these, 107 completed data on the LA preference for the exemplar procedures; $91 / 112$ (81.3\%) were from consultants, $7 / 112(6.3 \%)$ from fellows, $10 / 112$ from registrars (8.9\%) and 4/112 (3.6\%) from other grades. Ninety-six $(86 \%)$ responders were $30-49$ years of age and $14(21 \%)$ were $50-65$ years old.

Overall $22.8 \%$ (95\% CI: $18.7-25.2 \%$ ) of surgeons preferred LA for VR procedures. For macular hole procedures $33.6 \%$ (95\% CI: $29.1-38.2 \%$ ) of surgeons preferred LA, $26.2 \%$ (95\% CI: $19.9-30.4 \%$ ) for vitrectomy for diabetic haemorrhage, $23.3 \%$ (95\% CI: $17.5-21.5 \%)$ for vitrectomy, cryopexy and gas procedures, and $21.4 \%$ (95\% CI: 17.5-25.4\%) for buckling procedures.

Significantly fewer surgeons $(9.35 \%)$ preferred LA for rebuckling procedures (95\% CI: $6.5-12.1 \% ; p<0.001)$. A breakdown of LA usage is shown in Table 1.

Attitudes to the use of LA also varied: $52 / 107$ (48.6\%; 95\% CI: $43.7-53 \%$ ) of surgeons felt that patients were intolerant to longer operations; 68/111 (61.2\%; 95\% CI: $56.6-65.8 \%$ ) that LA was more painful/stressful for their patients, $69 / 112$ (62.7\%; $95 \%$ CI: $58.1-67.3 \%)$ that LA was more stressful for the surgeon, $70 / 107$ (65.4\%; $95 \% \mathrm{CI}$ : $60.8-70.2 \%)$ that buckling was more difficult, $74 / 105$ (69.1\%; 95\% CI: $64.6-73.2 \%)$ that redo surgery is compromised, $86 / 109$ (78.0\%; 95\% CI: $74.9-82.1 \%)$ that teaching is more difficult, $86 / 109$ (78.9\%; $95 \% \mathrm{CI}$ : $74.9-82.1 \%)$ that younger patients tolerate LA poorly, but 75/109 (71.4\%; 95\% CI: $67.5-75.8 \%)$ said that sedation was rarely necessary.

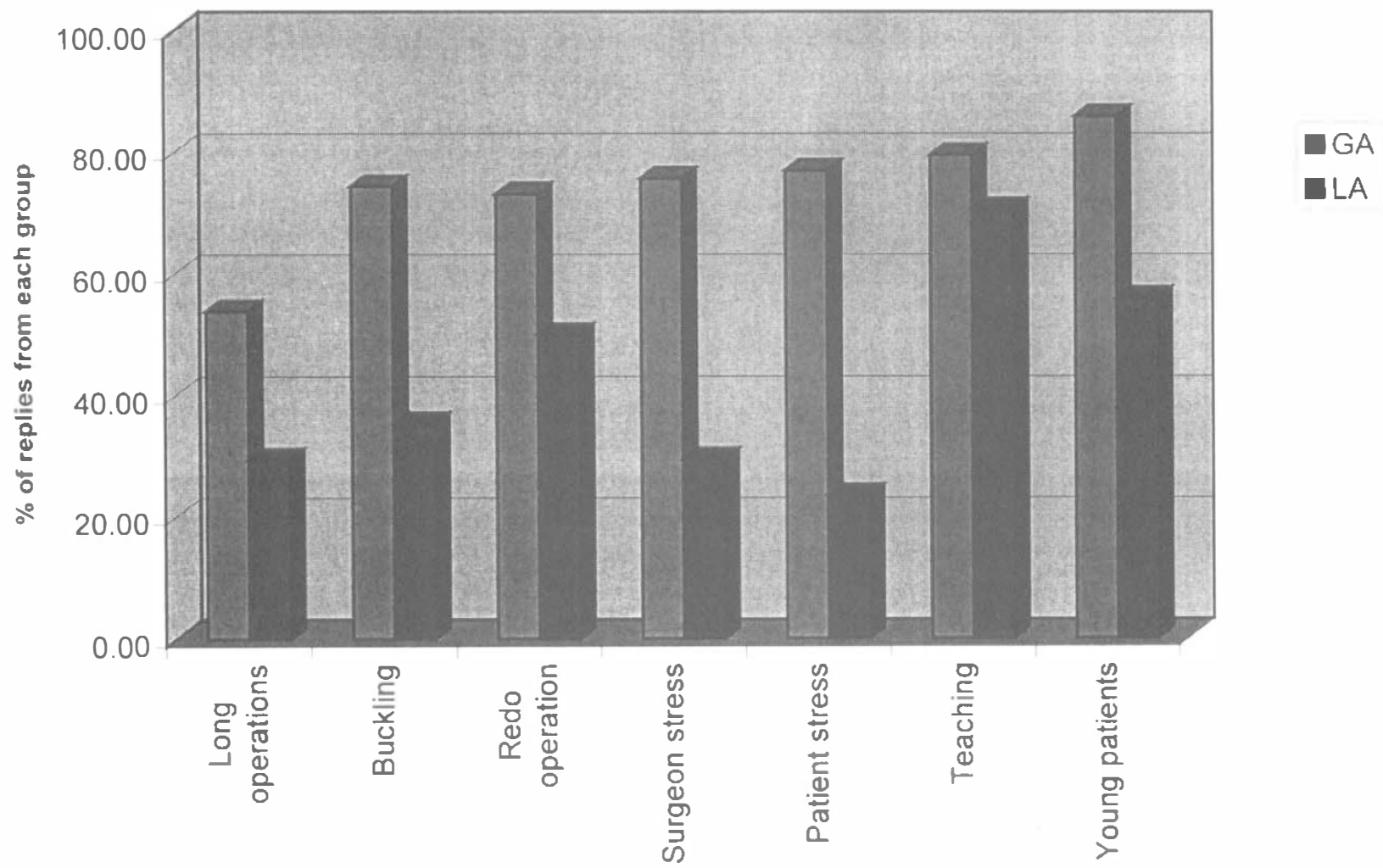

Fig. 1. Comparison between the attitudes of surgons routinely using local anaesthesia $>50 \%$ of the time $(L A, \mathrm{n}=34)$ and those routinely using general anaesthesia $>50 \%$ of the time (GA, $n=78$ ). To compare the attitudes the data are presented as percentage of replies from surgeon in each group. The original questions may be found in the Methods section. All difference were $\mathrm{P}<0.05$ apart from Teaching and Young patients ( $\mathrm{p}=0.1$ ). 


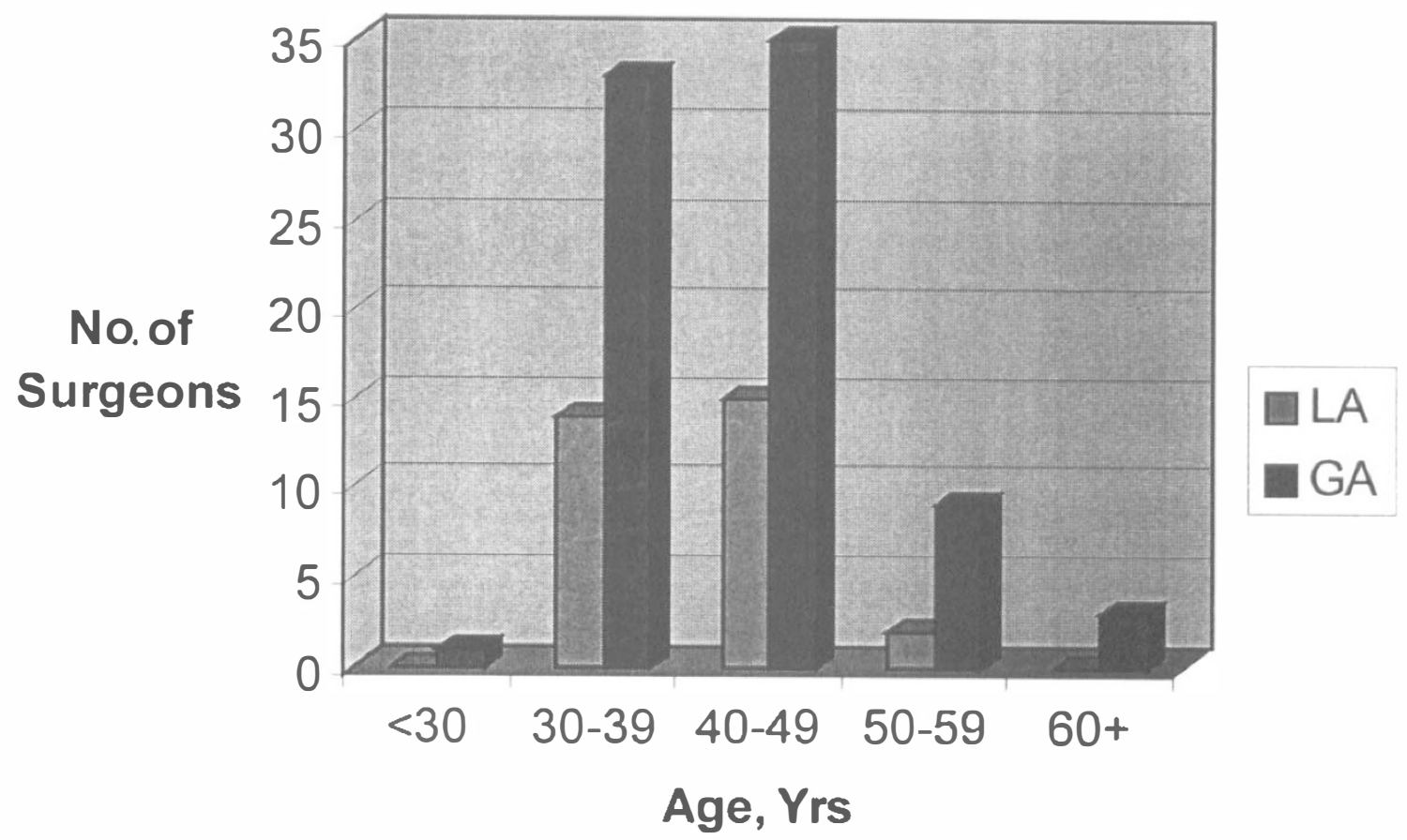

Fig. 2. Use of local anaesthesia (LA) or general anaesthesia (GA) versus age of surgeon. There is no correlation between the age of the surgeon and a preference for $L A(\mathrm{p}>0.05)$.

When surgeons were separated by use of LA for primary retinal detachment operations into those who routinely use LA ( $>50 \%$ of operations) $(n=34)$ and those who routinely use GA for $>50 \%$ of operations $(n=78)$, significant differences in attitude emerged (Fig. 1): 10 $(29.4 \%)$ vs $42(53.8 \%)$ of surgeons felt patients were intolerant to longer operations; 8 (23.5\%) vs 60 (76.9\%) that LA was more painful/stressful for their patients; 10 $(29.4 \%)$ vs $59(75.6 \%)$ that LA was more stressful for the surgeon; $12(35.2 \%)$ vs $58(74.6 \%)$ that buckling was more difficult; $17(50 \%)$ vs $57(73.3 \%)$ that redo surgery is compromised; $10(55.8 \%)$ vs $67(85.9 \%)$ that younger patients tolerate LA poorly; $24(70.6 \%)$ vs $62(79.4 \%)$ that teaching is more difficult with LA and $29(85.8 \%)$ vs 46 $(58.7 \%)$ that sedation was rarely necessary with LA. All these differences reached statistical significance $(p<0.01)$. However, there was no significant difference in the age of the two groups $(p=0.1)$ (Fig. 2).

\section{Discussion}

This survey received replies from $57 \%$ of UK VR surgeons; $81 \%$ of responders were consultants. The high reply rate is comparable to other LA studies and is a reasonable reflection of practice in the UK. ${ }^{11}$

Results showed that $22.8 \%$ of surgeons preferred to use LA for VR procedures, $33.6 \%$ preferred it for macular hole surgery but only $9.35 \%$ for re-buckling operations. These results are broadly in line with a straw poll taken at the BEAVRS meeting in 1996, when members showed their preference for GA. ${ }^{7}$ Recent reports have shown that there is a high patient acceptability for the use of LA for
VR surgery and that the speed of the operation and turnaround is improved without affecting surgical outcome. ${ }^{7,12}$ In this study we found that surgeons regularly using LA have different attitudes to those using regularly using GA. Surgeons using LA found patient and surgeons stress levels were low, they were less worried about the length of operations and were happy to perform buckling and re-buckling surgery under LA. Both groups agreed that operations on younger patients and teaching were relative contraindications to LA. However, unlike some reports from the United States, ${ }^{5,6}$ most UK surgeons thought sedation unnecessary.

Comments indicated there were many factors in choosing to develop a LA service. The attitudes of the nursing and anaesthetic team were important, bad experiences with LA when training were also noted, and some surgeons reported the absence of an anaesthetist on call for use of LA for out-of-hours surgery. There were no comments regarding the cardio-pulmonary reflex or retrobulbar haemorrhage preventing surgery during an emergency.

The uptake of LA for VR surgery has several similarities to that of LA for cataract surgery. ${ }^{13}$ In 1992 Hodgkins et al. ${ }^{13}$ found that only $20 \%$ of cataract surgeons used LA for most cases and that sedation was given by $45 \%$. They identified several reasons why surgeons preferred GA. When the use of LA was reassessed in $1999,{ }^{14} 76 \%$ of cases were carried out under LA with $5.8 \%$ needing sedation. In some units the use of GA for routine cataract surgery has stopped completely. We may see a similar picture developing for the use of LA for routine VR surgery over the coming years. 


\section{Conclusion}

The use of local anaesthesia for cataract surgery is now widely accepted. In this paper we have tried to identify some of the reasons vitreoretinal surgeons still prefer general anaesthesia. The operations are significantly longer and more painful, but with modern local anaesthetic techniques such as sub-Tenon's and anterior retrobulbar injections, high levels of anaesthesia can be maintained for $2-3 \mathrm{~h}$. Patient tolerance is often limited by the comfort of the operating table rather than the operation. Local anaesthesia has the advantage of rapid rehabilitation and posturing post-operatively as well as limiting disruption in diabetic control. However, its acceptance may rest not only with the surgeon but the anaesthetist and theatre team.

\section{References}

1. Yildirim R, Aras C, Ozdamar A, Bahcecioglu H. Silicone oil removal using self-sealing corneal incision under topical anesthetic. Ophthalmic Surg Lasers 1999;30:24-6.

2. Yepez J, Yepez J, Arevalo J. Topical anesthesia in posterior vitrectomy. Retina 2000;20:41-5.

3. Wilson D, Barr C. Outpatients and abbreviated hospitalisation for vitreoretinal surgery. Ophthalmic Surg 1992;21:119-22.
4. Davis DB 2nd, Mandel M. Posterior peribulbar anesthesia, an alternative to retrobulbar anesthesia. J Cataract Refract Surg 1986;12:182-4.

5. Sharma T, Gopal L, Sunil P, Shanmugam M, Badrinath S, Mukesh B. Parabulbar anesthesia for primary vitreoretinal surgery. Ophthalmology 1997;104:425-8.

6. Benedetti S, Agostini A. Peribulbar anesthesia for vitreoretinal surgery. Retina 1994;14:277-80.

7. Rao P, Wong D, Groenewald C, McGalliard J, Jones A, Ridges $P$. Local anaesthesia for vitreoretinal surgery: a case control study of 200 cases. Eye 1998;12:407-11.

8. Kwok A, Van Newkirk M, Lam D, Fan D. SubTenon's anesthesia in vitreoretinal surgery. Retina 1999;19:291-6.

9. Kirkby G, Benson M, Callear A, Loo A. Letter re: Local anaesthesia for vitreoretinal surgery: a case control study of 200 cases. Eye 1999;13:122.

10. Isernhagen R, Michels R, Glaser B, Bustros S, Enger C. Hospitalisation requirements after vitreoretinal surgery. Arch Ophthalmol 1988;106:767-70.

11. Eke T, Thompson J. The national survey of local anaesthesia for ocular surgery. I. Survey methodology and current practice. Eye 1999;13:189-95.

12. Mein C, Woodcock M. Local anesthesia for vitreoretinal surgery. Retina 1990;10:47-9.

13. Hodgkins P, Luff A, Morrell A, Teye B, Featherston T, Fielder A. Current practice of cataract extraction and anaesthesia. $\mathrm{Br}$ J Ophthalmol 1992;76:323-6.

14. Eke T, Thompson J. The national survey of local anaesthesia for ocular surgery. II. Survey methodology and current practice. Eye 1999;13:196-204. 